\title{
Electrochemical Behavior During the Zirconium Conversion Coating Formation on AISI 1006 Steel
}

\author{
Juliana dos Anjos-Moraes ${ }^{a, b}$, Alexandre Giacobbo ${ }^{a} \mathbb{D}^{\mathbb{D}}$, Rita Sánchez-Tovar $^{b}$, Rafael Leiva García $^{b}$, \\ Jose García-Antón ${ }^{b}$, Jane Zoppas Ferreira ${ }^{a}$ \\ ${ }^{a}$ Programa de Pós-Graduação em Engenharia de Minas, Metalúrgica e de Materiais (PPGE3M), \\ Universidade Federal do Rio Grande do Sul, (UFRGS), Porto Alegre, RS, Brasil \\ ${ }^{b}$ Ingeniería Electroquímica y Corrosión, Departamento de Ingeniería Química y Nuclear, \\ Universitat Politècnica de València, Valencia, Spain
}

Received: May 02, 2018; Revised: June 10, 2019; Accepted: July 30, 2019

\begin{abstract}
This study investigated a conversion coating based on hexafluorozirconic acid solution on cold-rolled (AISI 1006) steel sheets, in situ, at different $\mathrm{pH}$ values and immersion times. Electrochemical characterization was carried out by electrochemical impedance spectroscopy (EIS) with hexafluorozirconic acid bath as the electrolyte. Laser scanning confocal microscopy (LSCM) was used to evaluate the morphology of the coating in situ, i.e., during the coating formation. According to the results, the polarization resistance (Rp) of the conversion coating is affected by the immersion time and by the $\mathrm{pH}$ of the conversion bath. The electrochemical analyzes point out conversion baths at $\mathrm{pH}$ between 3.5 and 4.5 and immersion times from 600 to $900 \mathrm{~s}$ as optimal operating conditions, achieving an average polarization resistance of $713 \pm 107 \Omega \mathrm{cm}^{2}$.
\end{abstract}

Keywords: Zirconium Conversion Coating, Polarization, Cold Rolled Steel, EIS.

\section{Introduction}

Metallic substrates receive organic coatings to improve their appearance and increase the protection against corrosion. The application of this coating is usually associated to a pretreatment to modify the metal surface in order to improve the organic coating adherence, thus increasing the protection against corrosion ${ }^{1}$. For many years, the industry has used phosphate and chromium-based conversion pretreatments on metal alloys such as mild steel and aluminum in order to achieve these objectives with satisfactory results ${ }^{2}$.

Phosphating is a conversion treatment in which the metal surface is covered by an insoluble phosphate layer obtained by immersing the metal into a diacid phosphate salt solution. For the purpose of applying painting, the phosphate conversion coating is usually associated with a chromium conversion coating, used as pore sealing, supplementing the protection obtained with the phosphate conversion coating ${ }^{3}$. The chromium conversion coating, in most cases, is obtained by immersing the phosphate-coated material (or the bare material) in an aqueous bath of hexavalent chromium. Both phosphate and chromium conversion processes generate highly pollutant effluents, namely, rinsing water and spent solutions, which need costly treatment and disposal methods for effluents and wastes.

In this sense, many efforts have been made to reduce or abolish phosphatization and chromium (VI) chromatization from the production processes ${ }^{4}$ by using, alternatively, silanes conversion coatings and chromium (III) chromatization ${ }^{5,6}$.
However, phosphate conversion coatings are still present as pre-coatings in white lines, automotive vehicles and urban and office furnishing, as well as in electric components.

More recently, a conversion coating resulting from the reaction of the metal surface with hexafluoride acid-based solutions has been used more often ${ }^{7-9}$. The conversion reaction produces a coat of zirconium oxide onto the metal substrate $^{10-13}$. The biggest advantage of this treatment is the decrease of both quantity and toxicity of the effluents generated along the pre-coating process. Other advantages include more cutbacks on the stages of the process than the phosphate conversion and a reduction in energetic consumption since the zirconium conversion coating is performed at room temperature. It is also possible to apply this method with the same facilities formerly used for phosphate conversion coatings ${ }^{14}$.

The method for obtaining the conversion layers consists in the simple metal immersion in a conversion bath containing hexafluoride acids or aspersion on the metal ${ }^{15,16}$. Techniques such as electrochemical impedance spectroscopy (EIS) provide aspects of corrosion that can be verified by the polarization resistance values, which, in turn, are obtained by means of impedance diagrams from the raw substrate, pre-coated ${ }^{17,18}$ and painted (finished samples) ${ }^{19-23}$.

Recent researches ${ }^{24,25}$ have reported that parameters such as immersion time and $\mathrm{pH}$ of the solution modify the converted coat formation and its microstructure. In addition, depending on the treatment time, the coating performance and its morphology change, as well as the composition of the converted layer ${ }^{26,27}$. 
In fact, there are some studies employing hexafluorozirconic acid solutions as conversion bath for cold-rolled steel, but this matter is still not consolidated and more researches are necessary. More recently, a review about conversion coatings based on zirconium and/or titanium was published proving that there are still few studies on steels and none of them was carried out in situ ${ }^{28}$.

In face of these considerations, the aim of this paper is to characterize, in situ, the electrochemical behavior of carbon steel AISI 1006 immersed in a hexafluorozirconic acid conversion bath. The study was carried out during the coating formation and the treatment procedure was optimized by performing EIS and open circuit potential (OCP) studies. Parameters such as immersion time and $\mathrm{pH}$ of the conversion bath were correlated to understand the conversion coating formation on cold-rolled steel sheets in order to benefit the layer formation.

\section{Experimental}

\subsection{Materials and substrate preparation}

Cold-rolled AISI 1006 steel sheets with dimensions 100x50x1 mm, produced and supplied by Companhia Siderúrgica Nacional (CSN, Brazil), were used as substrate for conversion coating deposition. This substrate was used as received and the chemical composition, determined in an optical emission spectrometer (model Spectrolab from Spectro), is presented in Table 1. Before treatment, the samples were cleaned with an alkaline cleaning solution, prepared with $35 \mathrm{~g} \mathrm{~L}^{-1} \mathrm{NaOH}, 10$ $\mathrm{g} \mathrm{L}^{-1} \mathrm{Na}_{2} \mathrm{CO}_{3}$, and $5 \mathrm{~g} \mathrm{~L}^{-1}$ sodium dodecylbenzenesulfonate (Aldrich) at $85^{\circ} \mathrm{C}$ for $300 \mathrm{~s}$. Afterwards, they were rinsed with deionized water and dried in an oven at $120^{\circ} \mathrm{C}$.

Table 1. Element composition of cold-rolled AISI 1006 steel sheets.

\begin{tabular}{ccccccc}
\hline Element & $\mathrm{Fe}$ & $\mathrm{C}$ & $\mathrm{Mn}$ & $\mathrm{S}$ & $\mathrm{P}$ & $\mathrm{Al}$ \\
\hline wt.\% & balance & 0.078 & 0.043 & 0.037 & 0.030 & n.a.
\end{tabular}
n.a.: not analyzed.

All the conversion baths were prepared with $0.86 \mathrm{~g} \mathrm{~L}^{-1}$ $\mathrm{H}_{2} \mathrm{ZrF}_{6}$ (Alfa Aesar) diluted in deionized water. Treatments were performed at room temperature and $\mathrm{pH}$ values (2.5 - 5.0) were adjusted with a $1 \mathrm{M} \mathrm{NaOH}$ solution and immersion time ranged from 30 to $3600 \mathrm{~s}$. Sample codes and parameters evaluated in this study are presented in Table 2.

Table 2. Sample codes and parameters evaluated in this study.

\begin{tabular}{ccc}
\hline Sample code & Convention bath $\mathrm{pH}$ & Immersion time (s) \\
\hline A & 2.5 & \\
B & 3.0 & \\
C & 3.5 & $30-3600$ \\
D & 4.0 & \\
E & 4.5 & \\
F & 5.0 & \\
\hline
\end{tabular}

\subsection{Electrochemical analysis in situ}

EIS and OCP measurements were taken in situ, i.e., in the hexafluorozirconic acid bath at room temperature using a conventional three-electrode cell system via an Autolab PGSTAT 302N potentiostat. The NOVA 1.8 software was employed to analyze the data from the EIS measurements.

The working electrode was the as-received cold-rolled steel sheets with an exposed area of $0.44 \mathrm{~cm}^{2}$. A platinum electrode and a saturated calomel electrode (SCE) were used as counter and reference electrodes, respectively.

EIS and OCP measurements were held during the conversion coating formation, i.e., with samples immersed in the conversion bath. The frequency gap was between $10^{4} \mathrm{~Hz}$ and $1 \mathrm{~Hz}$ so that the diagrams could be reached in a short time. The OCP plot was used to simulate the time dependence of processes occurring on a microscopic scale on mild steel, comprising of steady and unsteady states ${ }^{11}$.

The measurements were repeated at least three times for each sample to ensure data reproducibility.

\subsection{Morphology}

The surface morphology of the film formation was investigated using a Laser Scanning Confocal Microscopy LEXT OLS3100 and the images were obtained during the conversion layer formation with a magnification of $80 \mu \mathrm{m}$.

\section{Results and Discussion}

\subsection{Electrochemical behavior: effect of the immersion time}

EIS measurements, in situ, were done to get more details about the film growing during the conversion layer formation. The Nyquist diagrams on Figure 1 show the characteristics of the conversion coating for sample $\mathrm{F}$, at different times, during the layer deposition by immersion in the hexafluorozirconic acid conversion bath at $\mathrm{pH}$ 5.0. The single incomplete semicircle for each immersion time is indicative of the occurrence of one reaction between electrolytes and steel surface. These curves present a similar shape; however, they differ in size. This behavior is an indicative that the same fundamental phenomenon is occurring over the immersion time but on different effective areas. Each semi-circle indicates the reaction between the steel and the electrolyte to form the conversion coating. According to Eivaz Mohammadloo et al. ${ }^{26}$, in Nyquist plots of coated samples, the appearance of a single semi-circle shows that the corrosion process involves a single time constant, indicating the existence of a double layer at the coating/electrolyte interface.

The diameter of the arc can be interpreted as polarization resistance ( $\mathrm{Rp}$ ) of the coating. Therefore, aiming to compare the corrosion behavior of all different immersion times, the $\mathrm{Rp}$ values from the Nyquist plots were employed as a measure of corrosion resistance. 


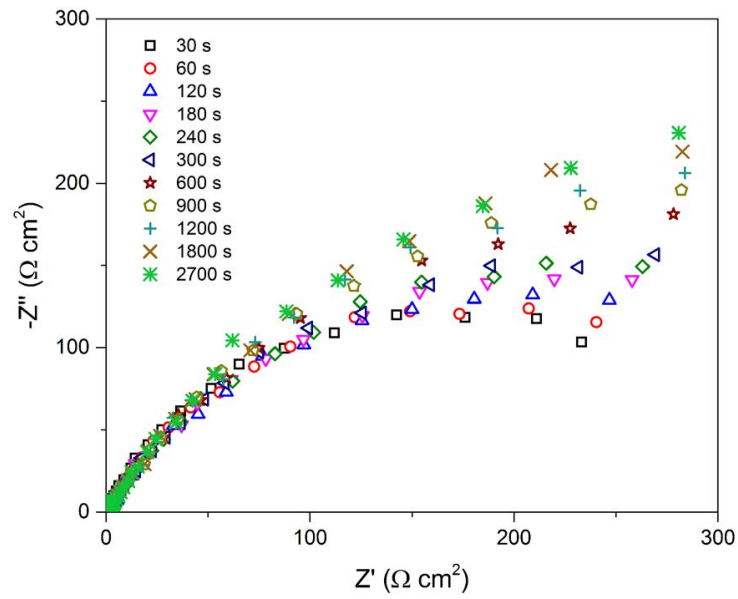

Figure 1. Nyquist plots for zirconium-treated steel samples at different immersion times, in conversion bath at pH 5.0 (sample F).

The smallest semi-circle corresponds to the shortest time (30 s) in contact with the conversion bath. Increasing the immersion time to $120,300,600,1200$ and 2700 s causes an increase in the angle of the semi-circle, i.e., the Rp increases from 354 to $421,511,591,689$ and $815 \Omega \mathrm{cm}^{2}$, respectively. This points out that by increasing the immersion time the thickness of the conversion coating increases, providing a better anti-corrosion performance. The Nyquist diagrams obtained from samples treated in hexafluorozirconic acid conversion baths in other $\mathrm{pH}$ values $(2.5,3.0,3.5,4.0$ and 4.5) presented a similar behavior to that obtained with $\mathrm{pH}$ 5.0, showed in Figure 1, that is, the diameter of the arc increases with the immersion time.

The corrosion potential during the conversion coating formation was monitored by means of OCP curves. Figure $2 \mathrm{a}$ shows the dynamic potential-time curves of the conversion coatings monitored at various immersion times in the conversion bath at different $\mathrm{pH}$ levels.

The potential of steel in contact with the conversion bath at pH 2.5 (sample A) decreased rapidly from an initial value of $-0.53 \mathrm{mV}$ vs (SCE) and attained an almost steady state of approximately $-0.57 \mathrm{mV}$ vs (SCE) around $600 \mathrm{~s}$.

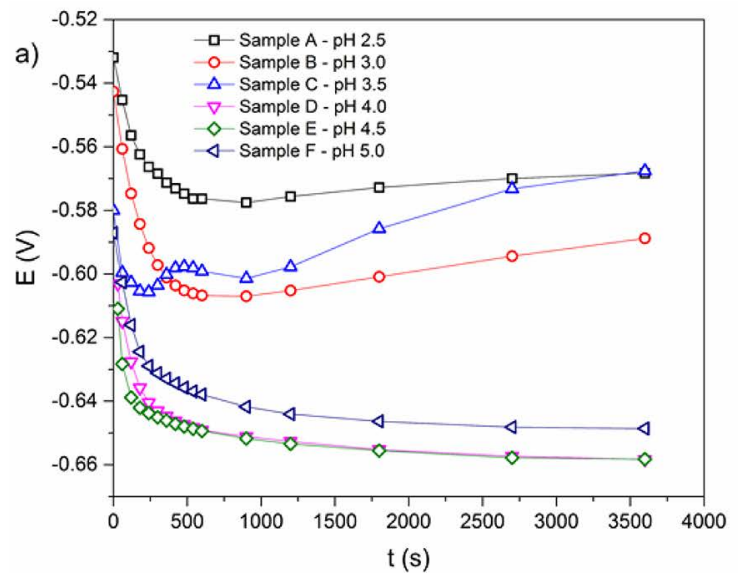

For samples $\mathrm{B}$ and $\mathrm{C}$, in $\mathrm{pH} 3.0$ and 3.5, respectively, the potential became more positive during the immersion time after $600 \mathrm{~s}$, being this behavior more pronounced for sample $\mathrm{C}$, suggesting a higher deposition rate with the conversion bath at $\mathrm{pH} 3.5$.

Increasing the $\mathrm{pH}$ to 4.0 (sample D), 4.5 (sample E) or 5.0 (sample F), the behavior is similar but in a more negative potential. For all the $\mathrm{pH}$ levels evaluated, the potential decreases in the same proportion and reaches the steady state approximately at the same time, around $600 \mathrm{~s}$, which indicates that all systems have similar behaviors, even at different $\mathrm{pH}$ levels.

As reported in previous studies ${ }^{14}$, at the beginning of OCP assays, the potential is unstable and usually exhibits a decrease over time, which is caused by the activation of the substrate surface by the conversion coating formation as a result of the dissolution of the metal substrate in the acid solution (conversion bath).

A temporal relation of the $\mathrm{Rp}$ values, which were calculated from the Nyquist diagrams, for all samples is shown at Figure $2 b$. These Rp values are related to the OCP plots at $\mathrm{pH}$ values presented on Figure 2a. The Rp from the samples A and B prepared in the conversion baths at $\mathrm{pH} 2.5$ and 3.0, respectively, were 139 and $170 \Omega \mathrm{cm}^{2}$ at the beginning, remained stable during the first $600 \mathrm{~s}$, and then gradually increased until they reached 274 and $358 \Omega \mathrm{cm}^{2}$ at $1 \mathrm{~h}$ of immersion time (3600 s).

For samples D, E and F obtained from the conversion baths at $\mathrm{pH}$ values of 4.0, 4.5 and 5.0, respectively, the $\mathrm{Rp}$ values were higher than the ones obtained at pH 2.5 and 3.0 (samples A and B). At the initial time, the Rp of these samples begun at about 315,319 and $354 \Omega \mathrm{cm}^{2}$, respectively, constantly increasing, reaching 905,854 and $783 \Omega \mathrm{cm}^{2}$ after $1 \mathrm{~h}$ of exposure $(3600 \mathrm{~s})$. Since the $\mathrm{Rp}$ is inversely proportional to the corrosion rate, the increase in the Rp values with the immersion time indicates that there is a protection against corrosion provided by the zirconic coating.

At $\mathrm{pH} 3.5$ (sample C), in the first $600 \mathrm{~s}$ the $\mathrm{Rp}$ is similar to the values obtained with $\mathrm{pH} 4.0$ (sample D), 4.5 (sample E) and 5.0 (sample F). However, the Rp continues increasing with the immersion time up to about $1200 \mathrm{~s}$.

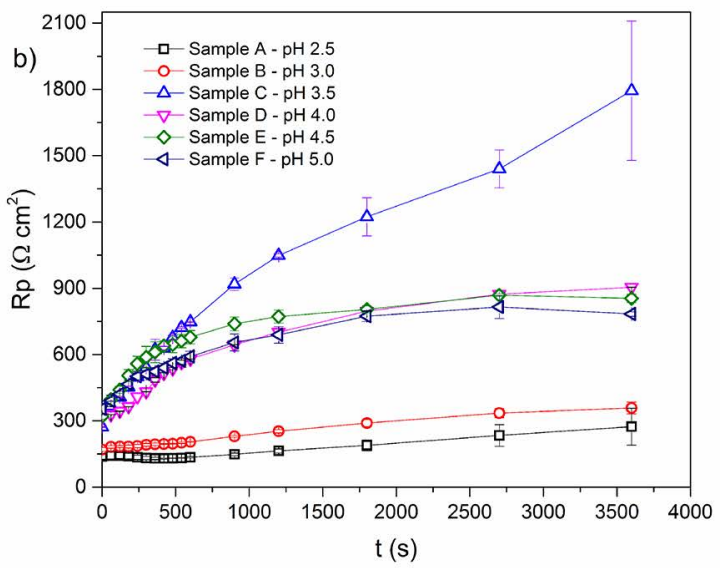

Figure 2. (a) OCP measurement and (b) polarization resistance trends of steel in treatment in hexafluorozirconic acid solution. 
From $1800 \mathrm{~s}$, there is a high instability in Rp values with the conversion bath at $\mathrm{pH} 3.5$ (sample C), as can be seen by the high values of standard deviations (Figure 2b). This behavior may be related to the competition between the substrate attack and the deposition of the conversion coating.

The $\mathrm{Rp}$ values for the samples D, E and F treated in conversion bath at $\mathrm{pH}$ 4.0, 4.5 and 5.0, respectively, exhibited similar behaviors, showing three regions: the first (until the initial $180 \mathrm{~s}$ ) with the highest growth rate; the second (from 180 to $\sim 900 \mathrm{~s}$ ) with a lower growth rate; and finally, the third region (from $900 \mathrm{~s}$ ), with null growth rate, i.e., a plateau. This behavior was also observed in other alloys. By using aluminum alloy (1050) samples, Golru et al. ${ }^{24}$ identified three typical regions in OCP diagram: in (i) short, (ii) medium, and (iii) long immersion time. In this work, these regions can be identified by analyzing the data from OCP and polarization resistance displayed in Figure 2. The first increase of the $\mathrm{Rp}$ (Figure $2 \mathrm{~b}$ ) is accompanied by a marked decrease in the initial potential (Figure 2a) until $120 \mathrm{~s}$ (i), and can be assigned by dissolution of the substrate and surface activation in the presence of fluorides in the solution ${ }^{22,24}$, resulting in reduction of dissolved oxygen molecules. This activation process can be defined by cathodic reactions (Eqs. (1) and (2)), and an anodic reaction (Eq. (3)):

$$
\begin{gathered}
2 \mathrm{H}^{+}+2 \mathrm{e}-\rightarrow \mathrm{H}_{2} \uparrow \\
\mathrm{O}_{2}+\mathrm{H}_{2} \mathrm{O}+4 \mathrm{e}^{-} \rightarrow 4 \mathrm{HO}^{-} \\
\mathrm{Fe} \rightarrow \mathrm{Fe}^{2+}+2 \mathrm{e}^{-}
\end{gathered}
$$

After the substrate surface activation, some oxides or reacted products were deposited on the surface of the cold-rolled steel in a medium immersion time of 180 to $360 \mathrm{~s}$ (ii), decreasing OCP reduction rate. This could be attributed to the formation of a zirconium layer on the metal surface and higher growing rate of this layer compared to the metal dissolution rate. Golru et al. ${ }^{24}$ also found that the region (ii) depends on the $\mathrm{pH}$ towards the OCP being constant for longer. The samples C, D, E and F submitted to the conversion bath with $\mathrm{pH}$ values of $3.5,4.0,4.5$ and 5.0 , respectively, showed a rapid activation stage, starting a conversion layer formation earlier than the $\mathrm{pH} 2.5$ (sample A) and 3.0 (sample B) (Figure 2). In this case, the Fe dissolution is more important than the coating deposition.

Eivaz Mohammadloo et al. ${ }^{26}$ argued that when the immersion time increases the deposition occurs to form a more compact film, thus increasing its thickness. They proposed the following electrochemical reaction for formation of zirconium-based conversion layer on steel substrate (Eq. 4):

$$
\begin{gathered}
\mathrm{H}_{2} \mathrm{ZrF}_{6}+\mathrm{Fe}+2 \mathrm{H}_{2} \mathrm{O} \rightarrow \mathrm{ZrO}_{2} \\
+\mathrm{Fe}^{2+}+4 \mathrm{H}^{+}+6 \mathrm{~F}^{-}+\mathrm{H}_{2} .
\end{gathered}
$$

Conversion layer compounds on the metal surface, composed by zirconium oxide and/or hydroxide, increase surface oxygen concentration of the substrate resulting in an increment of the surface donor properties ${ }^{23}$.

In region (iii), Golru et al. ${ }^{24}$ assumed that the layer deterioration may have occurred at longer immersion times as a result of the conversion coating degradation.

\subsection{Electrochemical behavior: Effect of the solution's pH}

Electrochemical impedance spectroscopy was also used to evaluate the electrochemical behavior depending on the $\mathrm{pH}$ variation of the conversion bath. The electrical equivalent circuit for electrode-electrolyte interface is displayed in Figure 3. R1 = Rs represents electrolyte resistance, $R 2=R p$ represents polarization resistance at the coated metal-electrolyte interface, and CPE1 represents the double layer capacitance.

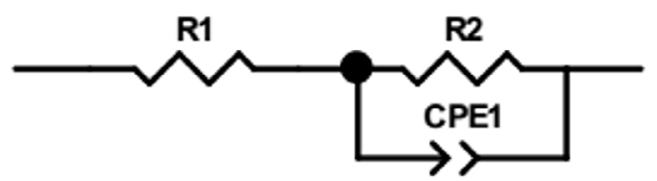

Figure 3. Electric circuit used to simulate the EIS results.

The capacitance values were calculated according to the following equation:

$$
C=\left(Y_{0} \times R^{1-n}\right)^{1 / n}
$$

in which $Y_{0}$ has magnitude of CPE (in $\mathrm{S}^{\mathrm{n}} \Omega^{-1} \mathrm{~cm}^{-2}$ ), $n$ is the CPE exponent, such as $n=\alpha /(\pi / 2)$, being $\alpha$ the constant phase angle of the CPE. The $n$ value has significance of phase change and can characterize different phenomena occurring on the surface. These phenomena could be a surface heterogeneity resulting from surface roughness, inhibitor adsorption, distribution of the active sites, impurities, metal dissolution or porous layer formation ${ }^{26}$.

Figure 4 displays a typical Nyquist plot, reflecting a simulation with the electric circuit model presented in Figure 3. Experimental and simulated data are in accordance.

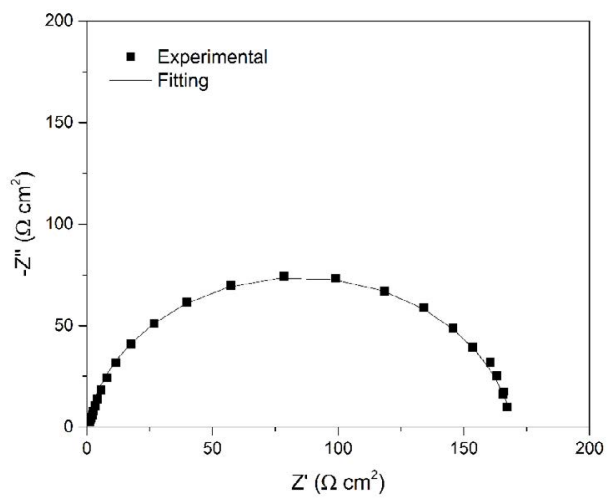

Figure 4. Nyquist diagram for the measured data in conversion bath at pH 2.5 (sample A) in $60 \mathrm{~s}$ of immersion. The solid line is the adjustment of the electric circuit model. 
Examining the Nyquist plots of treated steel surfaces in $300 \mathrm{~s}$ (Figure 5), one can verify that by increasing the $\mathrm{pH}$ of the conversion bath the polarization resistance $(\mathrm{Rp})$ was enhanced. This behavior is observed for conversion baths with $\mathrm{pH}$ up to 4.5. On the other hand, the conversion bath at $\mathrm{pH} 5.0$ (sample F) resulted in lower polarization resistances than the ones achieved with the conversion bath at $\mathrm{pH} 4.5$ (sample E). The strong influence of the conversion bath $\mathrm{pH}$ in promoting polarization resistance on steel is clearly illustrated in Figure 2b.

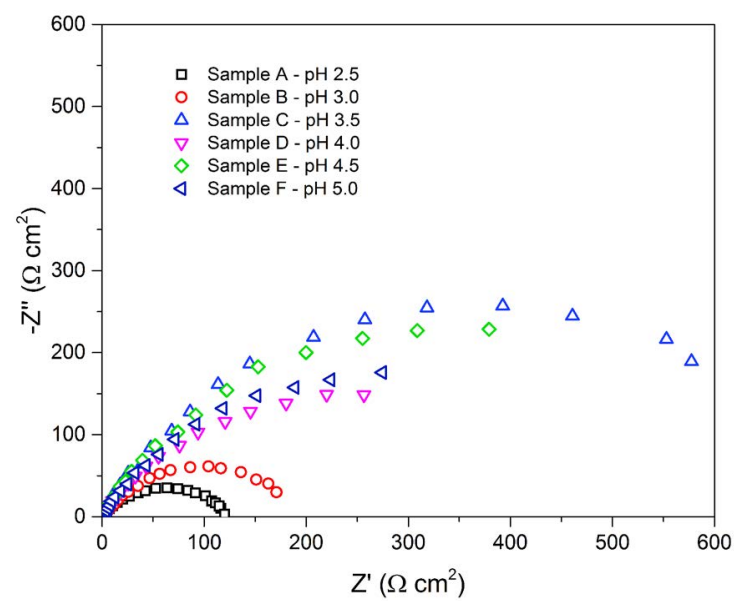

Figure 5. Nyquist plots for zirconium-treated steel samples at different $\mathrm{pH}$ values, in conversion bath at $600 \mathrm{~s}$ of immersion.
When the samples are in contact with the conversion bath, due to the reduction reaction of water and/or dissolved oxygen molecules, the local $\mathrm{pH}$ is increased at micro-cathodic sites favoring the deposition of the hydroxide layer on the metal surface. At very low $\mathrm{pH}$ values, 2.5 (sample A) and 3.0 (sample B) (Figure 2b), a competition between Fe oxidation and $\mathrm{Zr}$ precipitation occurs ${ }^{29}$.

At pH 3.5 (sample C) or more (samples D, E and F), a dynamic equilibrium between the anodic and cathodic reactions is reached, resulting in a higher growth rate of the coating layer. On the other hand, at $\mathrm{pH}$ values higher than 5.0, the ions produced from electrochemical reactions can cause a drop in polarization resistance of conversion coating ${ }^{27}$. This stage is related to the coating layer displacement and due to the chemical reaction of $\mathrm{Zr}$ hydroxide formation which, when immersed in bath for a longer period, can cause pitting corrosion, as can be seen in Figure 6d. In this sense, the best anticorrosive properties we found, yielding a polarization resistance of $713 \pm 107$ $\Omega \mathrm{cm}^{2}$, were achieved from samples $\mathrm{C}, \mathrm{D}$ and $\mathrm{E}$, which were treated in conversion baths at $\mathrm{pH} 3.5,4.0$ and 4.5, respectively, in immersion times between 600 and $900 \mathrm{~s}$. These results are in agreement with those reported in the literature for steels, which have presented the best results with conversion baths at $\mathrm{pH}$ values of $4.0^{29-32}$ and $4.5^{27,33}$.

An examination during the conversion coating formation on cold-rolled steel sheets was carried out by LSCM.
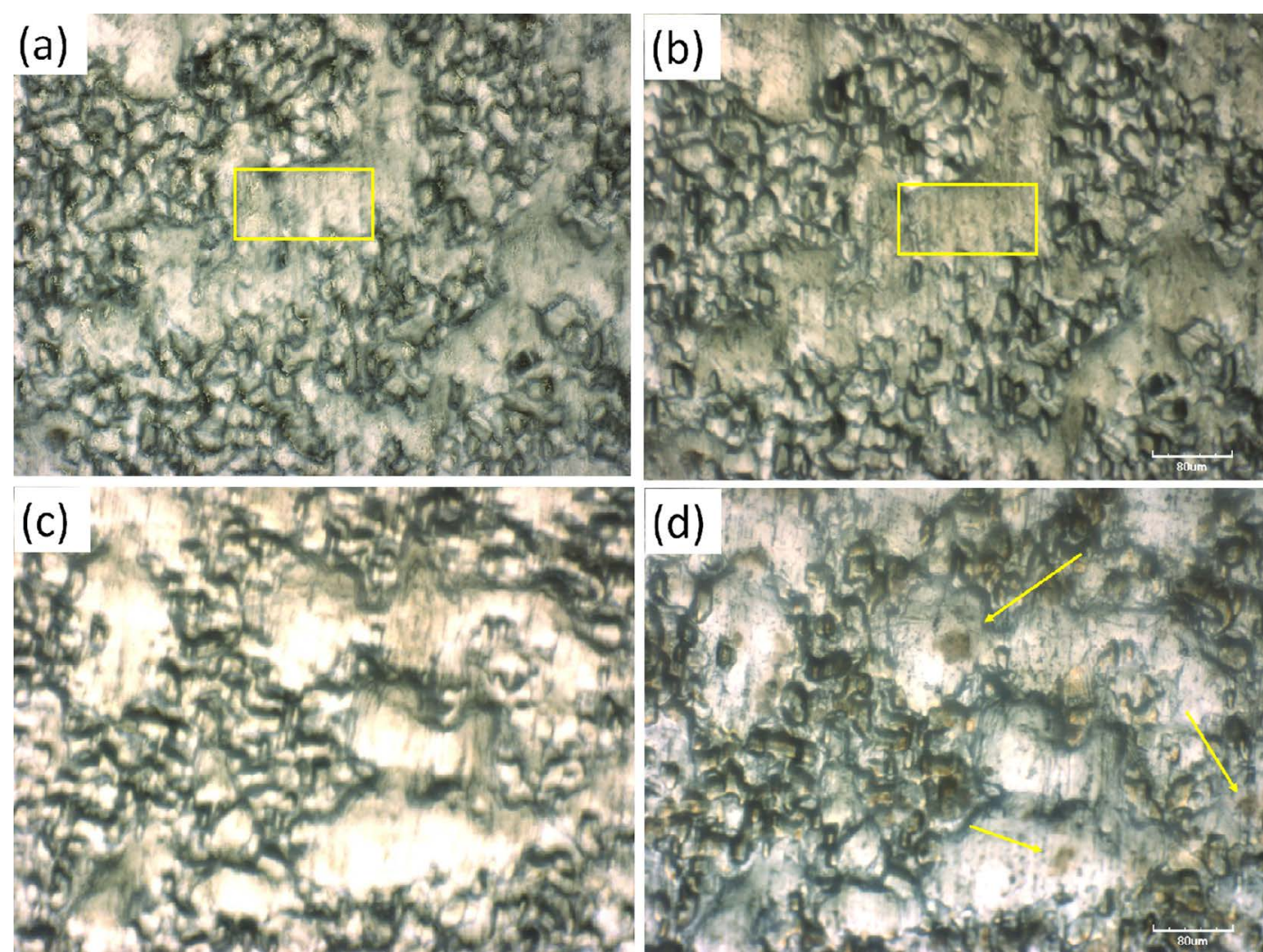

Figure 6. Photomicrographs with LSCM of the steel samples in the conversion bath (hexafluorozirconic acid solution) at $\mathrm{pH} 3.0$ in a) $30 \mathrm{~s}, \mathrm{~b}) 1 \mathrm{~h}$, and pH 5.0 in c) $30 \mathrm{~s}$, d) $1 \mathrm{~h}$, magnification of $80 \mu \mathrm{m}$. 
The photomicrographs displayed in Figure 6 show that variations in the conversion bath $\mathrm{pH}$ and in the immersion time resulted in the formation of a differentiated conversion layer on the steel.

For sample B, submitted to the conversion bath at $\mathrm{pH}$ 3.0, different tonalities were observed on the metal surface, lighter for a short immersion period (Figure 6a) and darker for the longest immersion time (Figure 6b). Besides, Figure $6 \mathrm{~b}$ shows an uniform staining on the substrate surface, which indicates an uniform deposition of the conversion coating. On the other hand, in sample F, which was treated with the conversion bath at pH 5.0 (Figures 6c and 6d), at the longest immersion time (Figure $6 \mathrm{~d}$ ), one can observe points distributed on the substrate surface, which is indicative of pitting corrosion (indicated by yellow arrows).

\section{Conclusions}

This study observed the electrochemical behavior of the zirconium conversion coating in situ, based on hexafluorozirconic acid solution, on cold-rolled steel substrates.

According to the EIS measurements during the conversion coating formation, the immersion time strongly affects the polarization resistance, which, in turn, increased at different rates in the $\mathrm{pH}$ range evaluated. This occurs when the ion exchange decreases and, consequently, the electrochemical resistance growth rate decreases and the dynamic equilibrium is reached.

Electrochemical tests showed that the polarization resistance increases by increasing the $\mathrm{pH}$ of the conversion bath and the immersion time. However, this behavior is observed up to $\mathrm{pH}$ values close to 4.5 , since at $\mathrm{pH} 5.0$, prolonged immersion times caused pitting corrosion, as shown in Figure 6d (indicated by yellow arrows). Summarizing, the best anticorrosive properties, characterized by a polarization resistance of $713 \pm 107 \Omega \mathrm{cm}^{2}$, were achieved with conversion baths at a $\mathrm{pH}$ range from 3.5 to 4.5 and immersion times between 600 and $900 \mathrm{~s}$.

The results show the strong relation of the $\mathrm{pH}$ of the conversion bath and of the immersion time with the conversion coating formation. Therefore, by optimizing these parameters the conversion coating can be improved.

\section{Acknowledgments}

The authors are grateful to CNPq and CAPES funders. The authors are grateful to Henrique Ribeiro Piaggio Cardoso for his contribution to the figures improvement.

\section{References}

1. Kerstner EK, Kunst SR, Beltrami LVR, Vega MRO, Scienza LC, Malfatti CF. Anticorrosive performance of commercial nanoceramic coatings on AISI 1010 steel. Materials Research. 2014;17(6):1497-1506.
2. Narayanan S. Surface pretreatment by phosphate conversion coatings - A review. Reviews in Advanced Materials Science. 2005;9(2):130-177.

3. Eppensteiner FW, Jenkins MR. Chromate conversion coatings. Metal Finishing. 1995;93(1 Suppl 1):460-473.

4. Kulinich SA, Akhtar AS. On conversion coating treatments to replace chromating for Al alloys: Recent developments and possible future directions. Russian Journal of Non-Ferrous Metals. 2012;53(2):176-203.

5. Oleinik SV, Kuznetsov YI. Corrosion inhibitors in conversion coatings. IV. Protection of Metals. 2007;43(4):391-397.

6. Yu HC, Chen BZ, Shi XC, Wu HY, Li B. EIS investigation of the deposition of trivalent chromium coatings on $\mathrm{Al} 6063$ alloy. Journal of Applied Electrochemistry. 2009;39(2):303-309.

7. Deck PD, Moon M, Sujdak RJ. Investigation of fluoacid based conversion coatings on aluminum. Progress in Organic Coatings. 1998;34(1-4):39-48.

8. Puomi P, Fagerholm HM, Rosenholm JB, Jyrkäs K. Comparison of different commercial pretreatment methods for hot-dip galvanized and Galfan coated steel. Surface and Coatings Technology. 1999;115(1):70-78.

9. Fedrizzi L, Deflorian F, Bonora PL. Corrosion behaviour of fluotitanate pretreated and painted aluminium sheets. Electrochimica Acta. 1997;42(6):969-978.

10. Nordlien JH, Walmsley JC, Østerberg H, Nisancioglu K. Formation of a zirconium-titanium based conversion layer on AA 6060 aluminium. Surface and Coatings Technology. 2002;153(1):72-78.

11. Lunder O, Simensen C, Yu Y, Nisancioglu K. Formation and characterisation of Ti-Zr based conversion layers on AA6060 aluminium. Surface and Coatings Technology. 2004;184(23):278-290.

12. Verdier S, van der Laak N, Dalard F, Metson J, Delalande S. An electrochemical and SEM study of the mechanism of formation, morphology, and composition of titanium or zirconium fluoride-based coatings. Surface and Coatings Technology. 2006;200(9):2955-2964.

13. Taheri P, Lill K, de Wit JHW, Mol JMC, Terryn H. Effects of Zinc Surface Acid-Based Properties on Formation Mechanisms and Interfacial Bonding Properties of Zirconium-Based Conversion Layers. The Journal of Physical Chemistry $C$. 2012;116(15):8426-8436

14. Moraes JA, Ferreira JZ, Meneguzzi A. Pré-revestimento de conversão à base de hexafluorzirconato. Corrosão \& Proteção. 2013;46:30-33.

15. Puomi P, Fagerholm HM, Rosenholm JB, Sipilä R. Optimization of commercial zirconic acid based pretreatment on hot-dip galvanized and Galfan coated steel. Surface and Coatings Technology. 1999;115(1):79-86.

16. Gusmano G, Montesperelli G, Rapone M, Padeletti G, Cusmà A, Kaciulis S, et al. Zirconia primers for corrosion resistant coatings. Surface and Coatings Technology. 2007;201(12):5822-5828.

17. Goeminne G, Terryn H, Vereecken J. Characterisation of conversion layers on aluminium by means of electrochemical impedance spectroscopy. Electrochimica Acta. 1995;40(4):479-486. 
18. Wang SH, Liu CS, Shan FJ. Corrosion behavior of a zirconiumtitanium based phosphonic acid conversion coating on AA6061 aluminium alloy. Acta Metallurgica Sinica (English Letters). 2008;21(4):269-274.

19. Fedrizzi L, Deflorian F, Boni G, Bonora PL, Pasini E. EIS study of environmentally friendly coil coating performances. Progress in Organic Coatings. 1996;29(1-4):89-96.

20. Fedrizzi L, Bianchi A, Deflorian F, Rossi S, Bonora PL. Effect of chemical cleaning on the corrosion behaviour of painted aluminium alloys. Electrochimica Acta. 2002;47(13-14):21592168 .

21. Mirabedini SM, Scantlebury JD, Thompson GE, Moradian $\mathrm{S}$. Adhesive strength of powder coated aluminium substrates. International Journal of Adhesion and Adhesives. 2005;25(6):484494.

22. Sharifi Golru S, Attar MM, Ramezanzadeh B. Effects of surface treatment of aluminium alloy 1050 on the adhesion and anticorrosion properties of the epoxy coating. Applied Surface Science. 2015;345:360-368.

23. Ghanbari A, Attar MM. The effect of zirconium-based surface treatment on the cathodic disbonding resistance of epoxy coated mild steel. Applied Surface Science. 2014;316:429434.

24. Sharifi Golru S, Attar MM, Ramezanzadeh B. Morphological analysis and corrosion performance of zirconium based conversion coating on the aluminum alloy 1050. Journal of Industrial and Engineering Chemistry. 2015;24:233-244.

25. Zhan W, Liu X, Lu C, Ouyang G. The Property of Colored Chemical Conversion on Various Metals with Iso-solution. Procedia Engineering. 2017;174:341-346.
26. Eivaz Mohammadloo H, Sarabi AA, Sabbagh Alvani AA, Sameie H, Salimi R. Nano-ceramic hexafluorozirconic acid based conversion thin film: Surface characterization and electrochemical study. Surface and Coatings Technology. 2012;206(19-20):4132-4139.

27. Eivaz Mohammadloo H, Sarabi AA, Mohammad Hosseini R, Sarayloo M, Sameie H, Salimi R. A comprehensive study of the green hexafluorozirconic acid-based conversion coating. Progress in Organic Coatings. 2014;77(2):322-330.

28. Milošev I, Frankel GS. Review - Conversion Coatings Based on Zirconium and/or Titanium. Journal of The Electrochemical Society. 2018;165(3):C127-C144.

29. Mohammad Hosseini R, Sarabi AA, Eivaz Mohammadloo H, Sarayloo M. The performance improvement of $\mathrm{Zr}$ conversion coating through $\mathrm{Mn}$ incorporation: With and without organic coating. Surface and Coatings Technology. 2014;258:437-446.

30. Adhikari S, Unocic KA, Zhai Y, Frankel GS, Zimmerman J, Fristad W. Hexafluorozirconic acid based surface pretreatments: Characterization and performance assessment. Electrochimica Acta. 2011;56(4):1912-1924.

31. Cerezo J, Vandendael I, Posner R, Lill K, de Wit JHW, Mol JMC, et al. Initiation and growth of modified Zr-based conversion coatings on multi-metal surfaces. Surface and Coatings Technology. 2013;236:284-289.

32. Ghanbari A, Attar MM. Surface free energy characterization and adhesion performance of mild steel treated based on zirconium conversion coating: A comparative study. Surface and Coatings Technology. 2014;246:26-33.

33. Asemani HR, Ahmadi P, Sarabi AA, Eivaz Mohammadloo H. Effect of zirconium conversion coating: Adhesion and anticorrosion properties of epoxy organic coating containing zinc aluminum polyphosphate (ZAPP) pigment on carbon mild steel. Progress in Organic Coatings. 2016;94:18-27. 